\title{
Survivorship care for cancer patients in primary versus secondary care: a systematic review
}

\author{
J. A. M. $\operatorname{Vos}^{1}$ (D) T. Wieldraaijer ${ }^{1}$ - H. C. P. M. van Weert ${ }^{1} \cdot$ K. M. van Asselt ${ }^{1}$
}

Received: 20 May 2020 / Accepted: 22 June 2020 / Published online: 19 August 2020

(C) The Author(s) 2020

\begin{abstract}
Background Cancer survivorship care is traditionally performed in secondary care. Primary care is often involved in cancer management and could therefore play a more prominent role.

Purpose To assess outcomes of cancer survivorship care in primary versus secondary care.

Methods A systematic search of MEDLINE and EMBASE was performed. All original studies on cancer survivorship care in primary versus secondary care were included. A narrative synthesis was used for three distinctive outcomes: (1) clinical, (2) patient-reported, and (3) costs.

Results Sixteen studies were included: 7 randomized trials and 9 observational studies. Meta-analyses were not feasible due to heterogeneity. Most studies reported on solid tumors, like breast $(N=7)$ and colorectal cancers $(N=3)$. Clinical outcomes were reported by 10 studies, patient-reported by 11 , and costs by 4 . No important differences were found on clinical and patientreported outcomes when comparing primary- with secondary-based care. Some differences were seen relating to the content and quality of survivorship care, such as guideline adherence and follow-up tests, but there was no favorite strategy. Survivorship care in primary care was associated with lower societal costs.

Conclusions Overall, cancer survivorship care in primary care had similar effects on clinical and patient-reported outcomes compared with secondary care, while resulting in lower costs.

Implications for cancer survivors Survivorship care in primary care seems feasible. However, since the design and outcomes of studies differed, conclusive evidence for the equivalence of survivorship care in primary care is still lacking. Ongoing studies will help provide better insights.
\end{abstract}

Keywords Cancer survivorship care $\cdot$ Primary care $\cdot$ Secondary care $\cdot$ Systematic review

\section{Background}

To date, the number of patients with incident cancer and cancer survivors is increasing, due to an aging population and the improvements in cancer screening, diagnosis, and treatment. Cancer survival has increased to over $60 \%$ between 2010 and 2020, as previously predicted by The Dutch Cancer Society [1]. In numerous countries worldwide, including the Netherlands, patients treated for cancer are initially included in a secondary care-based follow-up program, mainly focusing on the early detection of recurrences and treatment of

J. A. M. Vos

j.a.m.vos@amsterdamumc.nl

1 Department of General Practice, Amsterdam UMC, University of Amsterdam, Post-box 22660, 1100 DD Amsterdam, the Netherlands symptoms caused by the cancer or its treatment. However, survivorship care for cancer encompasses not only detection of recurrences but also the attention to rehabilitation (psychological and social support, integration in society and secondary prevention) as addressed by the Institute of Medicine (IOM) back in 2006 [2].

Following completion of cancer treatment, many patients experience unmet needs and symptoms [3] and primary care is often involved in management of these needs and symptoms, especially for the older population with comorbidities [4-9]. A more general approach is therefore likely to be favorable to patient outcomes [10]. Traditional core values of primary care, such as the continuity and coordination of care, can lend themselves for the improvement of cancer survivorship, but the role of primary care may vary depending on context and setting $[10,11]$.

Several reviews have been published on alternative survivorship care strategies, such as GP-, PCP-, nurse-led, patient- 
initiated, and shared care [12-16]. However, none have focused exclusively on survivorship care by physicians working in primary care. The aim of this systematic review is to provide an overview of the outcomes of survivorship care in primary- compared with secondary-based care.

\section{Methods}

\section{Study design and search strategy}

In February 2020, a systematic search was performed in MEDLINE and EMBASE to identify original studies on cancer survivorship care. General terms for survivorship care, including follow-up and aftercare, were used. In addition to the MEDLINE and EMBASE search, reference checking was performed to identify possible other relevant publications. (See Appendix 1 for the search strategy.)

\section{Eligibility, selection, and data extraction}

Original studies comparing cancer survivorship care in primary to secondary-based care were included. As health care systems differ around the globe, generalist professions providing primary- or community-based care, such as a general practitioner (GP), primary care physicians (PCPs), and family physicians (FPs), were included in this review. Studies reporting on patients of any age who were (curatively) treated for any type or stage of cancer were eligible. No restrictions were made on the type of outcomes. Economic evaluations of cancer survivorship care programs were also considered for inclusion. Studies on shared care and patient or physician preferences for survivorship care were excluded from this review.

All studies were screened on title and abstract by two independent researchers (JV and TW). Subsequently, complete texts were read to ensure inclusion criteria, and data were extracted. Data extraction was performed by one researcher (JV) based on a predefined data format. Disagreement between the two researchers on study selection and data extraction was resolved by discussion or, if necessary, by consulting a third independent researcher (KvA).

\section{Data analysis}

As we intended a broad and conclusive review, no restrictions were made on the type of patient, outcomes, or methodology, which resulted in substantial heterogeneity of studies. Therefore, meta-analyses were not feasible and a narrative synthesis was used.

Outcomes were grouped into three distinctive categories: (1) clinical outcomes as measured by medical records (including survival, serious clinical events, and documented followup care), (2) patient-reported outcomes as measured by patient questionnaires and interviews (including quality of life, symptoms, patient satisfaction, and self-reported receipt of survivorship care), and (3) costs of survivorship care programs (including societal and patient costs).

\section{Quality assessment}

A risk of bias analysis was performed for all included studies according to the designated quality assessment tools as advised by the Cochrane collaboration. The consort instrument was used for randomized clinical trials [17], and the ROBINSI for (non-randomized) observational studies [18].

\section{Results}

\section{Study selection}

The systematic search retrieved 1766 original studies (Fig. 1). Reference checking did not identify any additional studies. After title and abstract screening, full text of 42 studies was reviewed. Based on the predefined eligibility criteria, 16 studies were included in this review. Figure 1 illustrates the selection process.

\section{Quality assessment}

Risk of bias assessment revealed low risk of bias in 10 studies, intermediate in 3, and high risk of bias in 3 out of 16 studies (see Appendix Table 5). Risk of bias was often inherent to the design of the study, including selection, misclassification, recall, and interviewer bias.

\section{Baseline characteristics}

Table 1 shows the baseline characteristics of the included studies. Seven randomized controlled trials (RCTs) were included in this review [19-25]. Three studies of Grunfeld et al. were based on the same RCT, but reported on separate outcomes [20-22]. Other included studies were based on a type of observational study [26-34]. Most studies reported on patients with solid tumors, such as breast and colorectal cancers. The number of patients ranged from 98 in a retrospective cohort study [26] to 5009 in a quasi-experimental observational study [29]. Six studies reported on physicians working in primary care, of which two studies did not further specify the provider type [31,32]. The length of follow-up ranged from 1 to 15 years.

\section{Clinical outcomes}

Ten studies reported on clinical outcomes (see Table 2). No important differences were seen in survival between follow- 
Fig. 1 PRISMA flow diagram

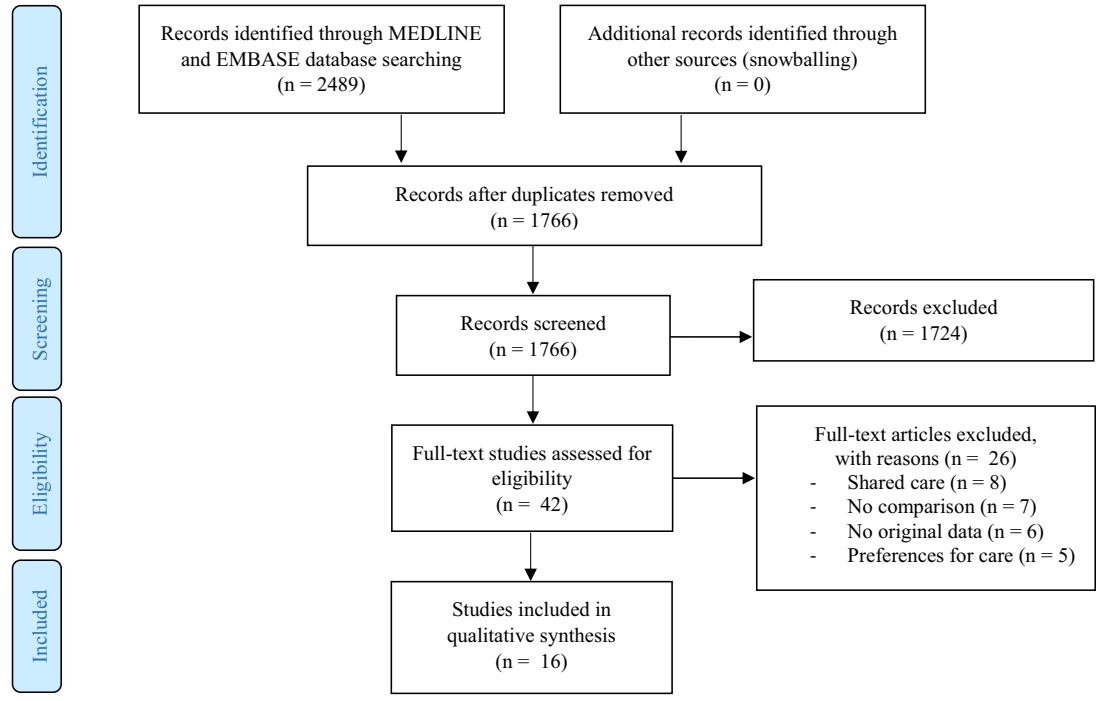

up strategies after 3 up to 15 years of follow-up [30, 33, 34]. Follow-up in secondary care was associated with shorter relapse-free survival (RFS) and higher likelihood of receiving palliative treatment with chemotherapy $(58 \%$ versus $34 \%, p=$ 0.03 ) in pancreatic cancer patients in a cohort study, in part because patients in secondary care had more advanced primary tumors [33]. Eight studies examined the occurrence of serious clinical events. No differences were seen relating to the number (and time of diagnosis) of recurrences and metastases [19, 20, 23-26], deaths [23, 25, 29], or other clinical events $[23,24,26]$ between primary and secondary care-based follow-up.

Documented follow-up care, as measured by adherence to medical guidelines and follow-up tests, was assessed by two RCT's. Murchie et al. [24] found that $98.1 \%$ of patients in primary-based care were seen according to guidelines versus $80.9 \%$ of patients in secondary-based care $(p=0.020)$. In the second study, patients in primary care were more likely to have one or more fecal blood tests (rate ratio 2.4, CI 1.4$4.44, p=0.003$ ), whereas patients in secondary care were more likely to have ultrasounds and colonoscopies, although it remained unclear whether or not this was done in accordance with follow-up guidelines [25].

\section{Patient-reported outcomes}

Eleven studies, including all six RCTs, measured patientreported outcomes (see Table 3). After adjustment for clinical and pathological covariates, no differences were seen in overall quality of life (QoL) and anxiety and depression between survivorship care strategies [19, 20, 23-26]. One observational study examined other bothersome symptoms, showing less fatigue among breast cancer patients in primary care $(62.0 \%$ versus $81.1 \%, p=0.005$ ) [31].
High levels of patient satisfaction and perception of care were found for survivorship care in both primary- and secondary-based care [22, 24-27, 32]. Using an adapted validated questionnaire, higher levels of patient satisfaction were found in primary care-based groups in two RCTs ( 9 out of 15 aspects by Grunfeld et al. [22] and 6 out of 15 by Murchie et al. [24]). In contrast, a questionnaire administered in an observational study [26] showed greater satisfaction in all 6 dimensions for breast cancer patients in secondary-based care $(p<0.05)$.

Five observational studies examined self-reported receipt of survivorship care by means of questionnaires and interviews. Disparate results were seen among primary- and secondary-based care, but there was no evidence for a more favorable strategy based on these results. Two studies showed a lower adherence to recommended periodic clinical examinations for breast cancer patients by physicians working in primary care (approximately $80 \%$ versus $90 \%$ in secondary care, $p<0.05)[31,32]$. In another study, patients in primary care were more likely to receive examination as is recommended by national guidelines $(58 \%$ versus $36 \%, p=0.004)$ [27]. No differences were seen in patient self-reported mammogram frequency [28, 31, 32]. Maly et al. [28] found a higher uptake of preventive tests, including Pap smear (AOR 2.90, CI 1.05-8.04, $p=0.040$ ) and colonoscopy (AOR 2.99, CI 1.5-8.51, $p=0.041$ ), among underserved breast cancer patients in primary care. Physicians in primary care helped more often with lifestyle improvements for colorectal cancer patients [27], but this was not the case among breast cancer patients [31].

\section{Costs}

Survivorship care in primary care was associated with lower societal and patient costs in all four studies that performed cost 
Table 1 Baseline characteristics of the included studies; (a) randomized controlled trials and (b) observational studies

\begin{tabular}{|c|c|c|c|c|c|}
\hline $\begin{array}{l}\text { Author, year, } \\
\text { country }\end{array}$ & Participants & Intervention & $\begin{array}{l}\text { Time since } \\
\text { diagnosis }\end{array}$ & Outcome & Baseline differences \\
\hline
\end{tabular}

(a) Randomized controlled trials

Augestad et al., Patients $<75$ years curatively 2013, treated for colon cancer,

Norway[19] Dukes' stage A, B, or C $(N=110)$. Transfer of care approximately 3-4 weeks after surgery.

Grunfeld et al., Women curatively treated for 1996, 1999 early-stage breast cancer I-II and 1999, $\quad(N=296)$. Transfer of care UK[20-22] after mean 3.4 months (SD 1.8).

Grunfeld et al., Woman curatively treated for 2006, $\mathrm{UK}[23]$ early-stage breast cancer I-III $(N=968)$. Transfer of care between 9 and 15 months after curative treatment.

Murchie et al., Patients curatively treated for 2010, UK[24] primary cutaneous melanoma $(N=142)$. Transfer of care after median 49 months (IQR 19-76).

Wattchow Patients curatively treated for et al., 2006, colon cancer, Dukes' stage Australia[25] A, B, or C $(N=203)$. Transfer of care approximately 4-6 weeks after surgery or chemotherapy.

(b) Observational studies

Baena-Canada Woman curatively treated for et al., 2013, early stage breast cancer 0-III Spain[26] $(N=98)$. Transfer of care 5 years after primary treatment.

Haggstrom et al., 2009, Colorectal cancer survivors $(N=416)$. Transfer of care USA[27] unknown.

Maly et al., Low-income women aged 2013, $\quad \geq 18$ years diagnosed with USA[28] breast cancer stage 0-III $(N=579)$. Transfer of care unknown.

Mittmann et al., Woman curatively treated for 2018 , any stage of breast cancer

Canada[29] $\quad(N=5009)$. Transfer of care unknown.

Parry et al., Patients diagnosed with stable 2015 , $\mathrm{UK}[30]$ stage A0 chronic lymphocytic leukemia $(N=246)$. Transfer of care unknown (after second outpatient visit).

Railton et al., Women aged $\geq 18$ years treated 2015, for stage I-III invasive breast Canada[31] cancer $(N=240)$. Transfer of care after median
GP- $(N=55)$ versus surgeon-led 2 years survivorship care $(N=55)$.

GP- $(N=148)$ versus hospital-based survivorship care $(N=148)$.

FP- $(N=483)$ versus specialist-led survivorship care $(N=485)$.

GP- $(N=53)$ versus hospital-based survivorship care $(N=89)$.

GP- $(N=97)$ versus surgeon-led 2 years survivorship care $(N=106)$.

5 years

patient-reported and costs

18 months

Primary care- $(N=60)$ versus hospital-based survivorship care $(N=38)$.

10 years

Comparison of physician specialty most often seen; no physician $(N=113), \mathrm{PCP}$ $(N=50)$, oncologist $(N=183)$, surgeon $(N=29)$ or gastroenterologist $(N=41)$.

Comparison of physician specialty most often seen; PCP only $(N=40)$, specialist only $(N=100)$ or shared care $(N=439)$.

PCP- $(N=2685)$ versus traditional cancer clinic-based survivorship care $(N=2324)$.

GP- $(N=105)$ versus hospital-based survivorship

1 year

36 months

25 months care $(N=141)$.

Median
66 months
(IQR 49-94)
in GP-group

From

$12 \geq$ versus cancer center-based survivorship care $(N=69)$.

48 months

\section{Clinical and} patient-reported

Clinical, patient-reported and costs

Clinical and patient-reported

Clinical and patient-reported patient-reported and costs

Patient-reported

Clinical and costs

No differences.

Patients in the hospital-group were older (59.0 versus 55.6 years) and had more stage I tumors $(50.6 \%$ versus $40.5 \%$ ).

No significant differences.

Patients in the GP-group lived further away to the hospital (27.6 miles (18.9-32.3) versus $10.1(2.3-25.9))$.

A trend towards higher levels of education was seen for patients in the surgeon-group (postsecondary school $22.5 \%$ versus $8.5 \%$ )

Patients in the primary care-group were older (60 versus 38 year, $p=0.002$ ) and received less chemotherapy $(62 \%$ versus $87 \%$, $p=0.001)$.

Patients were more inclined to receive care by a specialist if; stage III or IV disease $(p=0.03)$ and fewer comorbid medical conditions $(p=0.012)$

No baseline analyses.
Patient-reported
Patients in the GP-group were older (median age 71 versus $68, p=0.02$ ) and white cell count at diagnosis was higher (median 13.2 versus 10.4 , $p=0.018)$.

Patients in PCP-group were older $(59.1 \% \geq 50$ years versus $39.1 \%, p=0.005)$ and had more stage I disease stage 
Table 1 (continued)

\begin{tabular}{|c|c|c|c|c|c|}
\hline $\begin{array}{l}\text { Author, year, } \\
\text { country }\end{array}$ & Participants & Intervention & $\begin{array}{l}\text { Time since } \\
\text { diagnosis }\end{array}$ & Outcome & Baseline differences \\
\hline & $\begin{array}{l}11.3 \text { months (range } \\
1.8-42.0 \text { ). }\end{array}$ & & & & $\begin{array}{l}(50.9 \% \text { versus } 37.7 \% \text {, } \\
p=0.01) .\end{array}$ \\
\hline $\begin{array}{l}\text { Risendal et al., } \\
\text { 2016, } \\
\text { USA[32] }\end{array}$ & $\begin{array}{l}\text { Woman curatively treated for } \\
\text { breast cancer }(N=298) \text {. } \\
\text { Transfer of care unknown. }\end{array}$ & $\begin{array}{l}\text { PCP- }(N=94) \text { versus } \\
\quad \text { oncologist-led survivorship } \\
\quad \text { care }(N=204) \text {. }\end{array}$ & $\begin{array}{l}\text { Average } \\
\qquad \begin{array}{l}6.7 \text { years } \\
(\mathrm{SD}=0.98)\end{array}\end{array}$ & Patient-reported & $\begin{array}{l}\text { Patients in the PCP-group were } \\
\text { older }(26.6 \% \geq 65 \text { years ver- } \\
\text { sus } 8.8 \%, p<0.01) \text { and more } \\
\text { frequently had a lapse in in- } \\
\text { surance }(22.6 \% \text { versus } 9.6 \%, \\
p<0.01) \text { and in situ disease } \\
(33.0 \% \text { versus } 12.8 \%, \\
p<0.01) .\end{array}$ \\
\hline $\begin{array}{l}\text { Samawi et al., } \\
\text { 2018, } \\
\text { Canada[33] }\end{array}$ & $\begin{array}{l}\text { Patients aged } \geq 18 \text { years who } \\
\text { received at least one cycle of } \\
\text { adjuvant chemotherapy after } \\
\text { curative resection of } \\
\text { pancreatic adenocarcinoma } \\
(N=147) \text {. Transfer of care } \\
\text { unknown. }\end{array}$ & $\begin{array}{l}\text { PCP- }(N=50) \text { versus cancer } \\
\text { center-based survivorship } \\
\text { care }(N=97) .\end{array}$ & 15 years & Clinical & $\begin{array}{l}\text { Patients in the PCP-group had } \\
\text { more T1/T2 tumors }(38.0 \% \\
\text { versus } 21.6 \%, p=0.03)\end{array}$ \\
\hline $\begin{array}{l}\text { Peixoto et al., } \\
\text { 2014, } \\
\text { Canada[34] }\end{array}$ & $\begin{array}{l}\text { Patient aged } \geq 18 \text { years treated } \\
\text { for non-metastatic gastro- } \\
\text { esophageal cancer with } \\
\text { curative-intent }(N=292) \text {. } \\
\text { Transfer of care unknown. }\end{array}$ & $\begin{array}{l}\text { Comparison of } 4 \text { survivorship } \\
\text { care strategies; discharge to } \\
\text { GP }(N=89) \text {, care by } \\
\text { oncologist with clinical } \\
\text { assessments }(N=18) \text {, } \\
\text { specialist care with laboratory } \\
\text { investigations }(N=32) \text {, or } \\
\text { specialist care with imaging } \\
\text { or endoscopy }(N=153) \text {. }\end{array}$ & 3 years & Clinical & $\begin{array}{l}\text { Patients were more inclined to } \\
\text { receive care by a specialist if; } \\
\text { gastroesophageal junction or } \\
\text { gastric tumors }(p=0.001), \\
\text { primary lesions involving the } \\
\text { distal esophagus }(\mathrm{p}=0.001) \\
\text { specific histological subtypes } \\
(p=0.008) \text { and definitive } \\
\text { chemoradiotherapy } \\
(p=0.001) .\end{array}$ \\
\hline
\end{tabular}

$G P$ general practitioner, $F P$ family physician, $P C P$ primary care physician

analyses (see Table 4) $[19,21,26,29]$. The main cost driver in all studies was the mean cost per visit, including organizational and physician costs.

\section{Discussion}

In this review, similar effects on clinical and patient-reported outcomes were seen for survivorship care in primary- compared with secondary-based care. Although the evidence should be interpreted with caution, survivorship care in primary care seems feasible and results in lower costs.

\section{Comparison with existing literature}

A recent Cochrane review found little to no effects on predefined outcomes for RCTs comparing non-specialist (e.g., PCP-led, nurse-led, patient-initiated, and shared care) to specialist-led follow-up [12]. The certainty of evidence was generally low due to the limited amount of RCTs. Similarly to the Cochrane review, this review found no important differences in survivorship care between primary and secondary care relating to clinical (survival and recurrences) and patient-reported outcomes (quality of life and symptoms).

This review has identified additional outcomes in comparison with the Cochrane review relating to the content and quality of survivorship care. The content of survivorship care is examined by both documented follow-up care and self-reported receipt of survivorship care. Some differences were seen in these outcomes, especially relating to the adherence to guidelines and follow-up tests, but the results showed no favorite strategy. It remains unclear whether or not these differences may affect other outcomes, such as detection of recurrences and survival. Showing differences in these types of outcomes requires great numbers of patients and considerable follow-up time among often older patients with comorbidities, making this a challenging undertaking.

This review has examined patient's perceptions and satisfaction with care as indicators for the quality of survivorship care. High levels of quality of care were found for survivorship care in both primary- and secondary-based care. Two out of three RCTs showed higher levels of patient satisfaction with primary-based care, illustrating its feasibility $[22,24]$. The aggregation of these results provides us with the indication that survivorship care in primary care is similar to care by a specialist. Moreover, survivorship care in primary care led to lower costs in all studies that performed cost-analyses.

\section{Strengths and limitations}

Our review provides additional evidence to previous literature by focusing exclusively on survivorship care by physicians 
Table 2 Clinical outcomes of cancer survivorship care including (a) survival, (b) serious clinical events, and (c) documented follow-up care

Clinical Ref. Result

(a) Survival

Overall survival (OS)

Relapse-free survival (RFS)

(b) Serious clinical events

Recurrences and metastases

Deaths

Other clinical events

(c) Documented follow-up care

Adherence to medical guidelines and follow-up tests
[30] $69.5 \%(\mathrm{GP})$ versus $68.6 \%$ (hospital), $p=0.888$.

[33] In multivariate analyses a HR of 0.81 (PCP), CI 0.49-1.35, $p=0.43$.

[34] Reported as a figure, $p=0.34$, non-significance remained in multivariate analyses.

[30] $83.0 \%(\mathrm{GP})$ versus $78.1 \%$ (hospital) remained asymptomatic. $17.0 \%$ (GP) versus $21.9 \%$ (hospital) needed treatment, $p=0.424$. No differences were seen relating to the time to first treatment $(p=0.188)$.

[33] Patients in the PCP-group had longer RFS; in multivariate analyses a HR of 0.62 (PCP), CI 0.39-0.98, $p=0.041$. Patients in the PCP-group were less likely to receive palliative chemotherapy for their relapse (34\% versus $58 \%, p=0.03$ ).

[34] Reported as a figure, $p=0.59$, non-significance remained in multivariate analyses.

[19] 6 recurrences (GP) versus 8 (hospital), mean time to diagnosis was 35 days (GP) versus 45 days (hospital), $p=0.46$.

[20] $6.8 \%$ recurrences (GP) versus $10.8 \%$ (hospital), median time to diagnosis 22 days (GP) versus 21 days (hospital), median difference in time to diagnosis 1.5 days (range -13 to 22 ).

[23] $11.2 \%$ recurrences (FP) versus $13.2 \%$ (specialist), difference $2.02 \%, \mathrm{CI}-2.13-6.16 \%$.

[24] In both groups 1 diagnosis of recurrent melanoma.

[25] Recurrence rate of 7.1 per 1000 months (GP) versus 8.0 (surgeon), $p=0.92$, median time to detection was 9.5 (GP) versus 8.0 months (surgeon), $p=0.76$.

[26] $1.6 \%$ metastases (primary) versus $0 \%$ (hospital), $p=0.74$.

[23] $6.0 \%$ death of any cause (FP) versus $6.2 \%$ (specialist), difference $0.18 \%, \mathrm{CI}-2.90-3.26$.

[25] Death rate of 6.6 per 1000 months (GP) versus 5.4 (surgeon), $p=0.67$, median time to death 31 (GP) versus 20 months (surgeon), $p=0.69$.

[29] $18.6 \%$ death of any cause (PCP) versus $20.3 \%$ (specialist), $p=0.7$.

[23] Recurrence-related events (such as hypercalcemia or fracture); $3.5 \%$ (FP) versus $3.7 \%$ (specialist), difference $0.19 \%, \mathrm{CI}-2.26-2.65 \%$.

[24] New primary tumors (1 new primary in both groups).

[26] New primary tumor (5\% (primary) versus $10.4 \%$ (hospital), $p=0.67$ ), associated diseases $(46.7 \%$ (primary) versus $60.5 \%$ (hospital), $p=0.21$ ) and treatment effects $(22.3 \%$ (primary) versus $21.1 \%$ (hospital), $p=0.79$ ).

[24] Patients who visited a GP were more likely to be seen according to guideline ( $98.1 \%$ versus $80.9 \%$, $p=0.020$ ).

[25] Patients in the GP-group were more likely to visit their physician (1.27 times per quarter versus 0.84 times) and to have one or more FOBTS (rate ratio 2.4, CI 1.4-4.4, $p=0.003$ ). Patients in the surgeon group were more likely to have ultrasounds (rate ratio 0.5 , CI $0.3-1.0, p=0.040$ ) and colonoscopies (rate ratio 0.7 , CI $0.5-1.0, p=0.027$ ). No differences were seen relating to other surveillance tests, including CEA, $\mathrm{X}$-ray and CT-scan.

$G P$ general practitioner, $F P$ family physician, $P C P$ primary care physician

working in primary care and by including non-randomized studies in the results. By performing a non-restrictive search and selection strategy, two additional outcomes relating to the content and quality of survivorship care have been identified in comparison with the recent Cochrane review. The search strategy, including reference checking, provides a sensitive search result.

There are some limitations that need to be addressed. Inherent to the design of some studies, differences were seen in baseline characteristics. Older patients and patients with prognostic better disease stage were sometimes more likely to receive follow-up in primary care [26, 27, 30-34]. Despite adjusting for covariates, these differences might have influenced outcomes. Due to the substantial heterogeneity in outcomes and methodology, no data could be pooled for meta-analyses, hampering the interpretation of results. However, using a narrative synthesis, no important differences were seen relating to clinical and patient-reported outcomes. These results are in line with previous reviews [12-16]. 
Table 3 Patient-reported outcomes of cancer survivorship care including (a) quality of life, (b) symptoms, (c) patient satisfaction and perception of care, and (d) self-reported receipt of survivorship care

$\begin{array}{lll}\text { Patient-reported Result } & \text { Rethod }\end{array}$

(a) Quality of life (QoL)

[19] EORTC QLQ C-30, EuroQol-5D, and EQ VAS at baseline up to 24 months.

[20] SF-36 and EORTC QLQ C-30 at baseline, mid- and end-of-trial.

[23] SF-36 at baseline up to 60 months.

[24] SF-36 at baseline and 12 months. 24 months.

[26] SF-36 (administered once more than 5 years after treatment).

(b) Symptoms

Anxiety and depression [20] HADS at baseline, mid- and end-of-trial.

[23] HADS at baseline up to 60 months.

[24] HADS at baseline and 12 months.

[25] HADS at baseline, 12- and 24 months.

Other bothersome symptoms

[31] One-time structured telephone interview.

(c) Patient satisfaction and perception of care

[22] Adapted satisfaction questionnaire at baseline, mid-, and end of trial (Cronbach's alpha $=0.70$ ).

[24] Patient questionnaire at baseline and 12 months (Cronbach's Alpha $=0.70$ ).

[25] PSVQ at 24 months (previously validated).

[26] Questionnaire (administered once, more than 5 years after treatment, Cronbach's Alpha $=0.88$ ).

[27] Adapted patient questionnaire on perceptions of follow-up 2-5 years after diagnosis.

[32] Computer-aided telephone interview on perception of follow-up.

(d) Self-reported receipt of survivorship care
Adherence to medical
guidelines and
[27] Patient questionnaire on visits, tests and examinations $2-5$ years after diagnosis.

follow-up tests

[28] Patient survey on receipt of preventive care at baseline, 6, 18 and 36 months after diagnosis.

[31] One-time structured telephone interview on receipt of follow-up.

[32] Computer-aided telephone interview on receipt Patients who visited a PCP were less likely to receive a clinical breast exam of follow-up.
No differences in overall QoL, effects on subscales in favor of GP in role functioning (mean difference $-5.1(\mathrm{CI}-9.7$ to -0.5$), p=0.02$ ), emotional functioning $(-3.7$ (CI -6.8 to -0.6$), p=0.01)$ and pain (4.5 (CI $0.8-8.2)$, $p=0.01)$.

No differences on any subscale.

No differences on any subscale.

No differences on any subscale.

No differences on any subscale.

No differences on any subscale after adjustment for age and chemotherapy.

Anxiety scale difference 0.4 (CI -0.3 to 1.2 ), depression scale difference 0.4 (CI-0.2, to 1.1).

Reported as a figure; no differences.

8 patients were diagnosed as anxious (GP) versus 13 (hospital) $(p=0.868), 3$ patients as depressed (GP) versus 5 (hospital) $(p=0.912)$.

Median anxiety score 4.0, IQR 5.0 (GP) versus 5.0, IQR 4.5 (surgeon) $(p=0.106)$, median depression score 4.0, IQR 5.0 (GP) versus 3.0, IQR 4.0 (hospital) $(p=0.796)$.

Patient who visited a PCP had less fatigue $(62.0 \%$ versus $81.1 \%, p=0.005)$. No differences for other symptoms (arthralgias, hot flashes, memory loss, vaginal dryness, insomnia, paresthesias and depression).

Patients who visited a GP had greater satisfaction on 9 out of 15 aspects (relating to service delivery, consultation and continuity of care).

Patient who visited a GP had greater satisfaction on 6 out of 15 aspects (relating to service delivery, consultation and continuity of care), the mean score was 26.4, CI 24.9-27.9 (GP), versus 33.5, CI 32.5-34.4 (hospital), the change in mean summary score was $-5.96, \mathrm{CI}-8.09-3.89(\mathrm{GP})$, versus $0.29, \mathrm{CI}$ $-1.49-2.08$ (hospital), indicating higher satisfaction with GP $(p<0.001)$.

No differences on any subscale.

Patients who visited a specialist had greater satisfaction on all 6 dimensions; health care attention $(p=0.001)$, attention by medical $(p=0.006)$ and nursing personnel $(p=0.016)$, recommendation of service $(p=0.019)$,

No differences in communication, coordination, nursing care, office staff and follow-up rating; non-significance remained in multivariate regression.

Women who visited an oncologist reported a marginally higher degree of care coordination $(81.9 \%$ versus $73.1 \%$, OR 1.8 , CI $1.0-3.5)$.

The number of visits in the past year varied by physician specialty $(p<0.001)$. Patients in the PCP-group were less likely to see a doctor for "follow-up medical tests" ( $68 \%$ versus $89 \%, p<0.001)$ and more likely to receive a physical examination (58\% versus $36 \%, p=0.004)$. PCPs more often helped with lifestyle improvements ( $83 \%$ versus $63 \%, p=0.015)$ and discussed diet ( $70 \%$ versus $48 \%, p=0.005)$.

Patients who visited a PCP only were more like to receive a Pap smear (AOR 2.90, CI 1.05-8.04, $p=0.040$ ) and colonoscopy (AOR 2.99, CI 1.5-8.51, $p=0.041)$. No differences were seen in receipt of mammogram $(p=0.109)$.

Patients who visited a PCP had fewer clinical examinations $(85.6 \%$ versus $95.7 \%, p=0.04$ ), no differences were seen in accessing physician for examination, receipt of mammograms, having an endocrine therapy plan, psychosocial and sexual health, lifestyle management or need for assistance with follow-up goals.

(79.6\% versus $90.2 \%$, OR 2.5, CI 1.2-5.5). No differences were seen in receipt of mammogram, X-ray, scans, physical exam or education about breast self-exam. Women who visited an oncologist reported more tumor marker (OR 3.0, CI 1.5-5.8) and other blood tests (OR 2.0, CI 1.1-3.5). information provision $(p=0.003)$ and respect/friendliness $(p=0.008)$.

$G P$ general practitioner, $P C P$ primary care physician 
Table 4 Costs of cancer survivorship care including (a) societal costs and (b) patient costs

Costs Ref. Method Result

(a) Societal costs

[19] Cost- and utilization questionnaire filled in by patients at baseline up Mean cost of follow-up per patient per follow-up cycle was £292 to 24 months (including visits, tests and events such as $\quad$ (GP) versus $£ 351$ (surgeon), $p=0.02$. Mean societal cost per pametastases). tient for 24 months follow-up was $£ 8233$, range $£ 7904$ to $£ 8619$ (GP), versus $£ 9889$, range $£ 9569$ to $£ 10,194$ (surgeon), mean difference in favor of GP $£ 1656, p<0.001$.

[21] Record-of-visit form filled in by doctors at baseline up to 18 months Mean total cost per patient for 18 months follow-up was £64.7, (including visits and tests). range £5.8-301.9 (GP) versus £195.1, range £62.0-737.4 (surgeon), mean difference $£ 130.4$ (range $£-149.1 ;-111.6$ ) in favor of GP, $p<0.001$. Difference mainly due to mean cost of visit (mean cost $£ 40.9$, range $£ 5.8-143.8$ (GP), versus $£ 174.1$, range $62.0-558.0$ (surgeon)).

[26] Direct costs based on a single national database (Consejería de Salud, Junta de Andalucía) (including visits and tests).

Total cost of follow-up per patient per year was mean $€ 112.86$, SD 77.54 (primary care), versus mean $€ 184.61$, SD 85.87 (hospital), $p=0.0001$. Difference mainly due to costs per visit (mean $€ 17.46$, SD 8.62 (primary), versus mean $€ 60.32$, SD 21.19 (hospital), $p<0.001)$.

[29] Direct costs based on multiple national databases (including visits, tests, medication and events such as hospitalization).

Mean annual total cost per survivor was CAD \$6575, CI \$5563 to $\$ 7587$ (PCP) versus $\$ 10,832$, CI $\$ 9947$ to $\$ 11,717$ (specialist), resulting in $\$ 4257$, CI $\$ 2928$ to $\$ 5587$, lower annual cost (39.3\% reduction) per survivor in the PCP group. A $22.1 \%$ reduction in overall median annual costs (\$2261 versus \$2903) was seen. Main cost drivers included hospitalization, physician visits, medications, and home care. The PCP group had lower mean annual costs for same-day surgery, cancer clinic visits, physician visits, medications, long-term care, and home care.

(b) Patient costs

[19] Cost- and utilization questionnaire filled in by patients at baseline up More patients had expenses relating to travel in the hospital-group to 24 months (including travel, out-of-pocket expenses and work loss). ( $£ 156.9$ versus $£ 76.7, p<0.001)$. No differences were seen relating to out-of-pocket expenses $(\mathrm{p}=0.10)$ or work loss $(p=0.45)$.

[21] Cost-questionnaire filled in by patients at baseline up to 18 months Patients in the GP-group were more frequently in paid employment (including travel, out-of-pocket expenses, work loss, child support and spent time for an appointment). (47.8\% versus $31.0 \%, p=0.023$ ), walked to their appointment ( $32.4 \%$ versus $1.6 \%, \mathrm{p}=0.000)$, spent less time getting to their appointment (13.1 $\mathrm{min}$ (SD 8.3) versus 26.7 (SD 15.9)), spent more time during the appointment (52.6 $\mathrm{min}$ (SD 22.1) versus 82.2 (SD 31.8)). Patients in the hospital-group took more time off work $(61.1 \%$ versus $32.3 \%, p=0.006)$ and had more out-of-pocket expenses (including parking fare, $11.0 \%$ versus $2.4 \%, p=0.008)$. No differences were seen in the proportion of patients losing wages $(p=0.24)$ or in need of child care $(p=0.06)$.

$G P$ general practitioner, $P C P$ primary care physician

\section{Implications for future practice and research}

As the number of cancer survivors is rapidly increasing and resources are limited [12-16], alternative survivorship care strategies for the hospital-based survivorship care are deemed desirable. This review showed that cancer survivorship care in primary care seems feasible and worthwhile to consider. However, the role and capacity of physicians in primary care can vary depending on context and setting [10,11]. Most studies were performed in the UK and Canada in which physicians work as gate-keepers to secondary health care services. In these countries, a publicly funded universal health care system is in place. Other studies were performed in countries such as the US and Spain in which the health care system is both publicly and privately funded, and the role of primary care could be less distinguished. The randomized trials that could be identified, were limited to countries with a universal health care system, so further research is warranted to evaluate whether the results of these trials are also applicable to other health care systems. Furthermore, both clinical and patient-reported outcomes might change over time and could be affected by the length of follow-up. Therefore, to assess durable effects of survivorship care, greater number of patients and considerable follow-up time in these trials would be preferable. Moreover, the impact on the work-load for primary care physicians needs to be evaluated in case of growing numbers of patients in primary care-based cancer survivorship care. 


\section{Conclusion}

This review presents a comprehensive overview of survivorship care in primary care. To our opinion, this review has underlined the feasibility of survivorship care in primary care or possibility of some form of cooperative care. However, delivering high-quality survivorship care will also put restraints on primary care. This requires not only sufficient funding but also investments in organization and staff. Further studies with adequate designs are needed.

Author contributions All authors contributed to the study conception. The literature search was performed by J.A.M. Vos in collaboration with a medical librarian (F. van Etten-Jamaludin) of the Amsterdam UMC. Data selection and analysis were performed by J.A.M. Vos, T. Wieldraaijer and K.M. van Asselt. The first draft of the manuscript was written by J.A.M. Vos. All authors read and approved the final manuscript.

\section{Compliance with ethical standards}

Conflict of interest The authors declare that they have no conflict of interest.

Ethical approval This article does not contain any studies with human participants performed by any of the authors.

\section{Appendix 1. Search strategy}

The following search strategy was used in MEDLINE. The search strategy was developed in collaboration with a medical librarian (FvE) of the Amsterdam UMC, location AMC. A total of 1766 studies were found from inception up to the 22nd of February of 2020.

\begin{tabular}{|c|c|c|c|c|}
\hline \multicolumn{5}{|c|}{ History } \\
\hline Search & Add to builder & Query & Items found & Time \\
\hline \#5 & Add & Search $((((\# 1)$ AND \#2) AND \#3) AND \#4 Sort by: Publication Date & 1385 & 09:49:37 \\
\hline$\overline{\# 4}$ & $\overline{\mathrm{Add}}$ & $\begin{array}{l}\text { Search ("Cohort Studies"[Mesh] OR “Aftercare"[Mesh] OR follow-up*[tiab] OR followup*[tiab] OR } \\
\text { aftercare[tiab] OR after-care[tiab] OR surveillance*[tiab] OR post-operat*[tiab] OR postoperat*[tiab] } \\
\text { OR post-surg*[tiab] OR postsurg*[tiab] OR post-treatment*[tiab] OR posttreatment*[tiab] OR } \\
\text { checkup*[tiab OR check up*[tiab]) Sort by: PublicationDate }\end{array}$ & 3096777 & 09:49:12 \\
\hline$\underline{\# 3}$ & $\underline{\text { Add }}$ & $\begin{array}{l}\text { Search ("Secondary Care"[Mesh] OR "Secondary Prevention"[Mesh] OR dermatologist*[tiab] OR } \\
\text { oncologist*[tiab] OR surgeon*[tiab] OR gastroenterologist*[tiab] OR urologist*[tiab] OR } \\
\text { specialistled[tiab] OR secondary care[tiab] OR secondary healthcare[tiab] OR secondary health } \\
\text { care[tiab] OR hospital care[tiab] OR hospital follow up[tiab] OR hospital-based follow-up[tiab] OR } \\
\text { cancer center*[tiab] OR specialist care[tiab]) Sort by: PublicationDate }\end{array}$ & 290700 & 09:48:59 \\
\hline$\# 2$ & $\underline{\text { Add }}$ & $\begin{array}{l}\text { Search ("Family Practice"[Mesh] OR "Primary Health Care"[Mesh] OR "Physicians, Primary } \\
\text { Care"[Mesh] OR "Physicians, Family"[Mesh] OR "General Practitioners"[Mesh] OR "General } \\
\text { Practice"[Mesh] OR family practi*[tiab] OR family care*[tiab] OR family healthcare*[tiab] OR family } \\
\text { health care*[tiab] OR primary care*[tiab] OR primary healthcare*[tiab] OR primary health care*[tiab] } \\
\text { OR general practi*[tiab] OR GP[tiab] OR GPs[tiab] OR PCP[tiab] OR PCPs[tiab] OR family } \\
\text { doctor*[tiab] OR family physician*[tiab]) Sort by: PublicationDate }\end{array}$ & 404255 & 09:48:49 \\
\hline \#1 & $\underline{\text { Add }}$ & $\begin{array}{l}\text { Search ("Neoplasms" [Mesh] OR "Cancer Survivors"[Mesh] OR neoplasms*[tiab] OR cancer*[tiab] OR } \\
\text { tumor*[tiab] OR tumour*[tiab] OR malignan*[tiab]) Sort by: PublicationDate }\end{array}$ & 4174383 & 09:48:35 \\
\hline
\end{tabular}

The search was subsequently translated and adapted for use in EMBASE. A total of 1104 studies were found in EMBASE (classic)

\# Searches

Results

1 exp Neoplasms/ or Cancer Survivors/ or (neoplasm* or cancer* or tumor* or tumor* or malignan*).ti,ab,kw.

2 general practice/ or general practitioner/ or exp. primary health care/ or (family practi* or family care* or family healthcare* or family health care* or primary care* or primary healthcare* or primary health care* or general practi* or GP or GPs or PCP or PCPs or family doctor* or family physician*).ti,ab,kw.

3 exp secondary health care/ or (dermatologist* or oncologist* or surgeon* or gastroenterologist* or urologist* or specialist led or secondary care or secondary healthcare or secondary health care or hospital care or cancer center* or specialist care or hospital follow up or hospital-based follow-up).ti,ab,kw.

4 cohort analysis/ or exp. aftercare/ or (follow-up* or followup* or aftercare or after-care or surveillance* or post-operat* or postoperat* or $3,217,165$ post-surg* or postsurg* or post-treatment* or posttreatment* or checkup* or check up*).ti,ab,kw.

$5 \quad 1$ and 2 and 3 and 4

6 limit 5 to conference abstract status

75 not 6

After removal of duplicates, a total of 1766 studies were screened on title and abstract 


\section{Appendix 2}

Table 5 Risk of bias assessment

\begin{tabular}{|c|c|c|c|c|c|c|c|c|}
\hline & 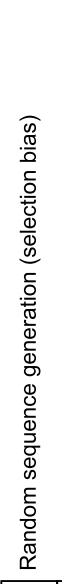 & 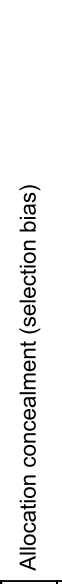 & 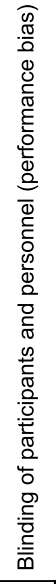 & 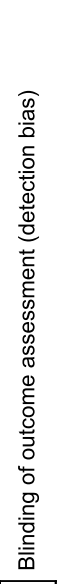 & 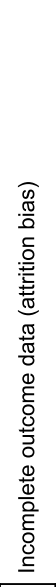 & 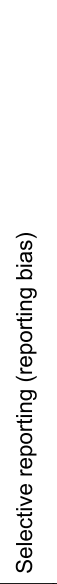 & 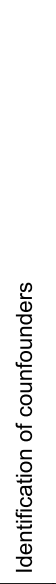 & 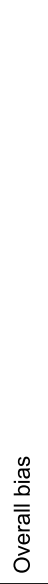 \\
\hline Augestad et al. 2013 & + & + & $?$ & $?$ & $\odot$ & + & + & + \\
\hline Grunfeld et al. 1996, 1999 and 1999 & + & + & $?$ & $?$ & + & + & $?$ & + \\
\hline Grunfeld et al. 2006 & + & + & $?$ & $?$ & + & + & + & + \\
\hline Murchie et al. 2010 & + & + & $?$ & $?$ & + & + & + & + \\
\hline Wattchow et al. 2006 & + & + & $?$ & $?$ & $\odot$ & + & + & + \\
\hline
\end{tabular}

Open Access This article is licensed under a Creative Commons Attribution 4.0 International License, which permits use, sharing, adaptation, distribution and reproduction in any medium or format, as long as you give appropriate credit to the original author(s) and the source, provide a link to the Creative Commons licence, and indicate if changes were made. The images or other third party material in this article are included in the article's Creative Commons licence, unless indicated otherwise in a credit line to the material. If material is not included in the article's Creative Commons licence and your intended use is not permitted by statutory regulation or exceeds the permitted use, you will need to obtain permission directly from the copyright holder. To view a copy of this licence, visit http://creativecommons.org/licenses/by/4.0/.

\section{References}

1. Knottnerus JA, Wijffels JF. SCK of KWF Kankerbestrijding. Aftercare in cancer: the role of primary care. Dutch Cancer Society's Signalling Committee on Cancer. 2011.

2. Hewitt M, Greenfield S, Stovall E. From Cancer patient to Cancer survivor: lost in transition. Washington, DC: National Academies Press; 2006.

3. Aziz NM. Cancer survivorship research: state of knowledge, challenges and opportunities. Acta oncologica (Stockholm, Sweden). 2007;46(4):417-32. https://doi.org/10.1080/ 02841860701367878 .

4. Khan NF, Watson E, Rose PW. Primary care consultation behaviours of long-term, adult survivors of cancer in the UK. Br J Gen

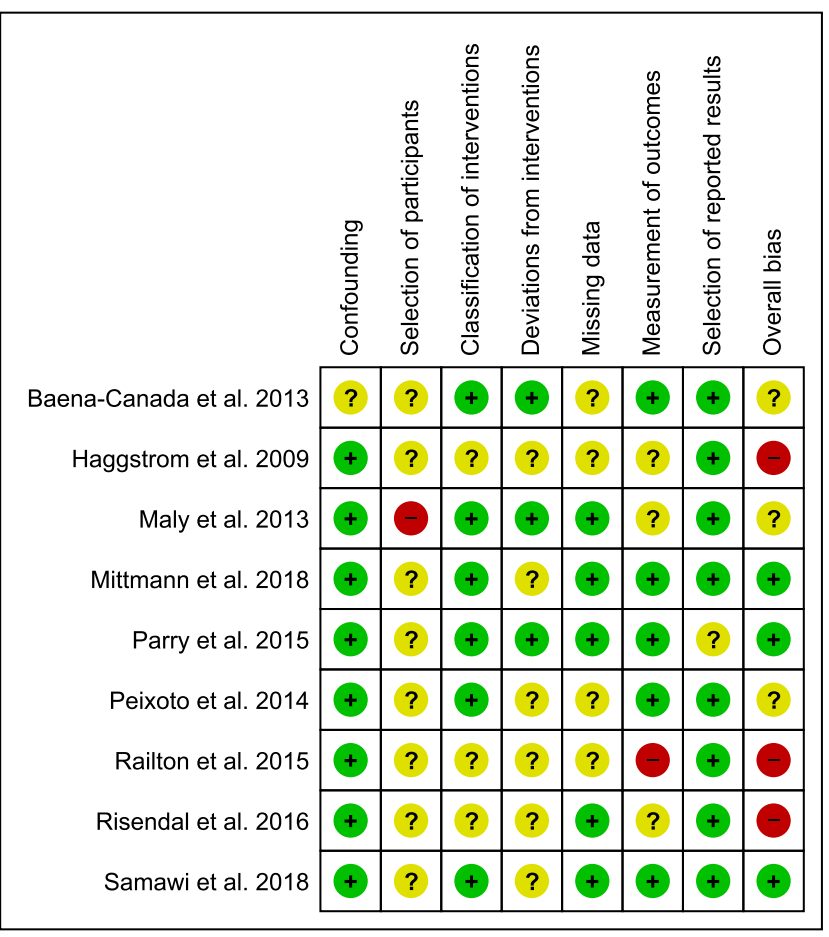

Pract. 2011;61(584):197-9. https://doi.org/10.3399/ bjgp11X561195.

5. Fidjeland HL, Vistad I, Gjelstad S, Brekke M. Exploring why patients with cancer consult GPs: a 1-year data extraction. BJGP open. 2019. https://doi.org/10.3399/bjgpopen19X101663.

6. Duineveld LA, Molthof H, Wieldraaijer T, van de Ven AW, Busschers WB, van Weert HC, et al. General practitioners' involvement during survivorship care of colon cancer in the Netherlands: primary health care utilization during survivorship care of colon cancer, a prospective multicentre cohort study. Fam Pract. 2019;36:765-70. https://doi.org/10.1093/fampra/cmz028.

7. Brandenbarg D, Roorda C, Groenhof F, de Bock GH, Berger MY, Berendsen AJ. Primary healthcare use during follow-up after curative treatment for colorectal cancer. European Journal of Cancer Care. 2017;26(3). https://doi.org/10.1111/ecc.12581.

8. Demagny L, Holtedahl K, Bachimont J, Thorsen T, Letourmy A, Bungener M. General practitioners' role in cancer care: a FrenchNorwegian study. BMC Research Notes. 2009;2:200. https://doi. org/10.1186/1756-0500-2-200.

9. Kenzik KM. Health care use during cancer survivorship: review of 5 years of evidence. Cancer. 2019;125(5):673-80. https://doi.org/ 10.1002/cncr.31852.

10. Rubin G, Berendsen A, Crawford SM, Dommett R, Earle C, Emery $\mathrm{J}$, et al. The expanding role of primary care in cancer control. Lancet Oncol. 2015;16(12):1231-72. https://doi.org/10.1016/S14702045(15)00205-3.

11. Adam R, Watson E. The role of primary care in supporting patients living with and beyond cancer. Current Opinion in Supportive and Palliative Care. 2018;12(3):261-7. https://doi.org/10.1097/spc. 0000000000000369 . 
12. Hoeg BL, Bidstrup PE, Karlsen RV, Friberg AS, Albieri V, Dalton $\mathrm{SO}$, et al. Follow-up strategies following completion of primary cancer treatment in adult cancer survivors. The Cochrane Database of Systematic Reviews. 2019;2019(11). https://doi.org/ 10.1002/14651858.CD012425.pub2.

13. Lewis RA, Neal RD, Williams NH, France B, Hendry M, Russell $\mathrm{D}$, et al. Follow-up of cancer in primary care versus secondary care: systematic review. The British Journal of General Practice. 2009;59(564):e234-47. https://doi.org/10.3399/bjgp09X453567.

14. Montgomery DA, Krupa K, Cooke TG. Alternative methods of follow up in breast cancer: a systematic review of the literature. Br J Cancer. 2007;96(11):1625-32. https://doi.org/10.1038/sj.bjc. 6603771

15. Taggart F, Donnelly P, Dunn J. Options for early breast cancer follow-up in primary and secondary care - a systematic review. BMC Cancer. 2012;12:238. https://doi.org/10.1186/1471-240712-238.

16. Davies NJ, Batehup L. Towards a personalised approach to aftercare: a review of cancer follow-up in the UK. Journal of Cancer Survivorship : Research and Practice. 2011;5(2):142-51. https:// doi.org/10.1007/s11764-010-0165-3.

17. Higgins JP, Altman DG, Gotzsche PC, Juni P, Moher D, Oxman $\mathrm{AD}$, et al. The Cochrane Collaboration's tool for assessing risk of bias in randomised trials. BMJ (Clinical Research ed). 2011;343: d5928. https://doi.org/10.1136/bmj.d5928.

18. Sterne JA, Hernan MA, Reeves BC, Savovic J, Berkman ND, Viswanathan M, et al. ROBINS-I: a tool for assessing risk of bias in non-randomised studies of interventions. BMJ (Clinical Research ed). 2016;355:i4919. https://doi.org/10.1136/bmj.i4919.

19. Augestad KM, Norum J, Dehof S, Aspevik R, Ringberg U, Nestvold T, et al. Cost-effectiveness and quality of life in surgeon versus general practitioner-organised colon cancer surveillance: a randomised controlled trial. BMJ Open. 2013;3(4). https://doi.org/ 10.1136/bmjopen-2012-002391.

20. Grunfeld E, Mant D, Yudkin P, Adewuyi-Dalton R, Cole D, Stewart J, et al. Routine follow up of breast cancer in primary care: randomised trial. BMJ (Clinical Research ed). 1996;313(7058): 665-9. https://doi.org/10.1136/bmj.313.7058.665.

21. Grunfeld E, Gray A, Mant D, Yudkin P, Adewuyi-Dalton R, Coyle $\mathrm{D}$, et al. Follow-up of breast cancer in primary care vs specialist care: results of an economic evaluation. Br J Cancer. 1999;79(7-8): 1227-33. https://doi.org/10.1038/sj.bjc.6690197.

22. Grunfeld E, Fitzpatrick R, Mant D, Yudkin P, Adewuyi-Dalton R, Stewart J, et al. Comparison of breast cancer patient satisfaction with follow-up in primary care versus specialist care: results from a randomized controlled trial. The British Journal of General Practice. 1999;49(446):705-10.

23. Grunfeld E, Levine MN, Julian JA, Coyle D, Szechtman B, Mirsky $\mathrm{D}$, et al. Randomized trial of long-term follow-up for early-stage breast cancer: a comparison of family physician versus specialist care. Journal of Clinical Oncology. 2006;24(6):848-55. https://doi. org $/ 10.1200 /$ jco.2005.03.2235.

24. Murchie P, Nicolson MC, Hannaford PC, Raja EA, Lee AJ, Campbell NC. Patient satisfaction with GP-led melanoma follow- up: a randomised controlled trial. Br J Cancer. 2010;102(10):144755. https://doi.org/10.1038/sj.bjc.6605638.

25. Wattchow DA, Weller DP, Esterman A, Pilotto LS, McGorm K, Hammett Z, et al. General practice vs surgical-based follow-up for patients with colon cancer: randomised controlled trial. Br J Cancer. 2006;94(8):1116-21. https://doi.org/10.1038/sj.bjc.6603052.

26. Baena-Canada JM, Ramirez-Daffos $\mathrm{P}$, Cortes-Carmona C, RosadoVarela P, Nieto-Vera J, Benitez-Rodriguez E. Follow-up of longterm survivors of breast cancer in primary care versus specialist attention. Fam Pract. 2013;30(5):525-32. https://doi.org/10.1093/ fampra/cmt030.

27. Haggstrom DA, Arora NK, Helft P, Clayman ML, Oakley-Girvan I. Follow-up care delivery among colorectal cancer survivors most often seen by primary and subspecialty care physicians. J Gen Intern Med. 2009;24(Suppl 2):S472-9. https://doi.org/10.1007/ s11606-009-1017-6.

28. Maly RC, Liu Y, Diamant AL, Thind A. The impact of primary care physicians on follow-up care of underserved breast cancer survivors. Journal of the American Board of Family Medicine. 2013;26(6):628-36. https://doi.org/10.3122/jabfm.2013.06. 120345 .

29. Mittmann N, Beglaryan H, Liu N, Seung SJ, Rahman F, Gilbert J, et al. Examination of health system resources and costs associated with transitioning cancer survivors to primary care: a propensityscore-matched cohort study. Journal of Oncology Practice. 2018. https://doi.org/10.1200/jop.18.00275.

30. Parry HM, Damery S, Mudondo NP, Hazlewood P, McSkeane T, Aung S, et al. Primary care management of early stage chronic lymphocytic leukaemia is safe and effective. QJM. 2015;108(10): 789-94. https://doi.org/10.1093/qjmed/hcv017.

31. Railton C, Lupichuk S, McCormick J, Zhong L, Ko JJ, Walley B, et al. Discharge to primary care for survivorship follow-up: how are patients with early-stage breast cancer faring? Journal of the National Comprehensive Cancer Network. 2015;13(6):762-71. https://doi.org/10.6004/jnccn.2015.0091.

32. Risendal BC, Sedjo RL, Giuliano AR, Vadaparampil S, Jacobsen PB, Kilbourn K, et al. Surveillance and beliefs about follow-up care among long-term breast cancer survivors: a comparison of primary care and oncology providers. Journal of Cancer Survivorship : Research and Practice. 2016;10(1):96-102. https://doi.org/10. 1007/s11764-015-0454-y.

33. Samawi HH, Yin Y, Lim HJ, Cheung WY. Primary care versus oncology-based surveillance following adjuvant chemotherapy in resected pancreatic cancer. Journal of Gastrointestinal Cancer. 2018;49(4):429-36. https://doi.org/10.1007/s12029-017-9988-8.

34. Peixoto RD, Lim HJ, Kim H, et al. Patterns of surveillance following curative intent therapy for gastroesophageal cancer. $\mathrm{J}$ Gastrointest Canc. 2014;45:325-33. https://doi.org/10.1007/ s12029-014-9601-3.

Publisher's note Springer Nature remains neutral with regard to jurisdictional claims in published maps and institutional affiliations. 